\title{
TRPM2 expression levels are associated with histological grading in patients with tongue squamous cell carcinoma
}

\author{
FUDONG ZHU ${ }^{1,2^{*}}$, XIAOBO CAI $^{3 *}$, XIN YANG $^{4}$, JIANFENG HE $^{5}$, CHENGZE WANG $^{1}$, \\ MINGXIANG WANG ${ }^{4}$, AILI SIMAITI ${ }^{4}$, WEI YANG ${ }^{3}$, XINQIANG ZHU $^{4}$ and PEILIN YU ${ }^{4}$ \\ ${ }^{1}$ Department of Oral and Maxillofacial Surgery, The Affiliated Stomatology Hospital, Zhejiang University School of Medicine; \\ ${ }^{2}$ Key Laboratory of Oral Biomedical Research of Zhejiang Province; Departments of ${ }^{3}$ Biophysic, \\ ${ }^{4}$ Toxicology and ${ }^{5}$ Oral and Maxillofacial Surgery, The First Affiliated Hospital, \\ Zhejiang University School of Medicine, Hangzhou, Zhejiang 310058, P.R. China
}

Received March 5, 2020; Accepted July 7, 2020

DOI: $10.3892 / \mathrm{mmr} .2020 .11417$

\begin{abstract}
Tongue squamous cell carcinoma (TSCC) accounts for a large proportion of cases of head and neck cancer. Transient receptor potential melastatin 2 (TRPM2) is a non-selective cation channel sensitive to oxidative stress. High TRPM2 expression has been reported in various types of cancer, including neuroblastoma, glioblastoma, non-small cell lung cancer and breast cancer. However, whether expression levels of TRPM2 are associated with aggressive clinical features in TSCC remains unclear. A total of 26 clinical sample tissues with TSCC were collected in the present study. The expression levels of the TRPM2 channel were determined by immunohistochemistry, western blot, and qPCR analysis. The content of malondialdehyde (MDA) and the activity of superoxide dismutase (SOD) were measured to reveal oxidative stress levels in TSCC tissues with different degrees of differentiation. The protein expression levels of caspase-8, Bcl-xL, Bax, caspase-9, cleaved caspase-9, caspase-3, cleaved caspase-3, poly [ADP-ribose] polymerase (PARP) and cleaved PARP were detected by western blot analysis. Analysis of the tissue specimens from 26 patients with TSCC showed that TRPM2 was not upregulated in all specimens. Notably, the expression levels of TRPM2 were associated with the histological grading of different tissues. The specimens with low TRPM2 expression were significantly associated with moderate or poor differentiation $(\mathrm{P}=0.003)$, and exhibited increased lipid peroxidation level and decreased SOD activity. Furthermore, the altered expression of pro- and anti-apoptotic
\end{abstract}

Correspondence to: Dr Peilin Yu, Department of Toxicology, Zhejiang University School of Medicine, 866 Yu Hang Tang Road, Hangzhou, Zhejiang 310058, P.R. China

E-mail: yupeilin@zju.edu.cn

${ }^{*}$ Contributed equally

Key words: tongue squamous cell carcinoma, transient receptor potential melastatin 2 , histological grading, oxidative stress, apoptosis proteins indicated a significant upregulation of apoptosis in TSCC tissues with low TRPM2 expression. These results suggested that low TRPM2 expression in TSCC may inhibit the ability of cells to adapt to or resist the oxidative stress, resulting in increased susceptibility to apoptosis. Therefore, the oxidative stress-sensitive TRPM2 channel may serve as a potent biomarker, and the present study provides insights into the underlying mechanisms of tumor cell differentiation.

\section{Introduction}

Tongue squamous cell carcinoma (TSCC) is a major type of malignant tumor of the oral cavity, accounting for 354,864 incident cases and $>177,000$ mortalities annually (1). In spite of great advances in diagnostic and therapeutic strategies during the past decades, patients are often diagnosed at advanced stages, and the mortality rate of TSCC remains high (2). Therefore, identifying and evaluating diagnostic and prognostic biomarkers for early disease diagnosis and treatment remains an urgent need.

The grading of tumors based on the degree of differentiation is usually the first level of histological assessment of TSCC (3). It considers the degree of keratinization, cellular and nuclear pleomorphism and mitotic activity. Tumors are generally divided into three categories: Well; moderately; and poorly differentiated (3). At present, the clinical evaluation of the differentiation degree of TSCC is primarily based on the 4th Edition of the World Health Organization Classification of head and neck tumors, which provides an international standard and important guide for oncologists and pathologists to evaluate therapies and clinical outcomes (4). The histological grading is widely regarded clinically as one of the key prognostic variables. However, tumor grading is often subjective and prone to vary among pathologists, and inadequate sampling from tumors often causes histological heterogeneity. Therefore, new predictors for cell differentiation are required (3).

Oxidative stress, characterized by an imbalance between the presence of relatively high levels of toxic reactive species, principally consisting of reactive oxygen species (ROS), and the activity of antioxidative defense mechanisms, is a common 
observation in a wide range of solid tumors, including TSCC (2). Transient receptor potential melastatin 2 (TRPM2), as the second member of the TRPM subfamily, is a non-selective cation channel sensitive to oxidative stress. A large number of studies have revealed that TRPM2, as an oxidative stress sensor, enables cells to sense and respond to oxidative stress, and regulate $\mathrm{Ca}^{2+}$ influx in response to oxidative stress $(5,6)$. Furthermore, TRPM2 has been suggested to serve pivotal roles in both physiological and pathological processes such as cell proliferation, survival, apoptosis, autophagy, cell cycle, migration and invasion (7).

Increasing evidence indicates that TRPM2 is aberrantly expressed in a variety of malignant tumors, including neuroblastoma (8-12), glioblastoma $(13,14)$, non-small cell lung cancer (15-18), melanoma (19,20), bladder cancer (21-23), prostate cancer (24-27), breast cancer (28-31), gastric cancer (32-35), pancreatic ductal adenocarcinoma $(36,37)$, endometrial carcinoma (38) and T cell leukemia (39). There are relatively fewer reports on the association between TRPM2 channel and oral malignant tumors. Zhao et al (40) identified that TRPM2 expression was absent in normal tongue squamous tissues, but was unregulated in tongue cancer tissues. In addition, the expression level of TRPM2 in TSCC SCC9 and SCC25 cell lines was remarkably increased as compared with normal tongue squamous cells (40). Selective knockdown of TRPM2 regulates expression levels of tumor-associated proteins and promotes cell apoptosis. These results indicate that TRPM2 expression may be significantly associated with TSCC. However, evidence from clinical data and research investigating the exact mechanism are still lacking.

In the present study, the association between TRPM2 expression and the clinical features of patients with TSCC was analyzed, and its association with TSCC histological grading was determined. Further evaluation of oxidative stress level and apoptosis-related proteins indicated that downregulation of the TRPM 2 channel may weaken the ability of cells to adapt to or resist oxidative stress, making cells more susceptible to apoptosis. Taken together, the results of the present study identified the TRPM2 channel as a useful predictor of tumor cell differentiation, and suggested that it may be a potential prognostic marker and therapeutic target for TSCC.

\section{Materials and methods}

Patients and tissue specimens. Clinical samples from 26 patients with primary TSCC were collected from July 2017 to August 2019 from the Affiliated Stomatology Hospital and The First Affiliated Hospital, Zhejiang University School of Medicine and each tissue sample was divided into normal tongue $(\mathrm{N})$, peritumor $(\mathrm{P})$ and squamous cell carcinoma tissue $(\mathrm{T})$. The distance between peritumor tissue and the boundary of the tongue squamous cell carcinoma tissue was $\sim 2 \mathrm{~cm}$. None of the patients had received any prior treatment for TSCC. All fresh tissue samples removed during surgery were fixed at room temperature for $48 \mathrm{~h}$ with $10 \%$ formalin for hematoxylin and eosin staining and immunohistochemistry, or preserved at $-80^{\circ} \mathrm{C}$ for subsequent protein extraction. The present study and experimental procedures were approved by the ethics committee of Zhejiang University School of Medicine, and conducted in strict accordance with Ethical examine methods for human biomedical research issued by the National Health and Family Planning Commission in 2016. Each patient included in the present study was informed in advance and provided written informed consent.

Hematoxylin and eosin $(H \& E)$ staining. Briefly, formalin-fixed paraffin-embedded tissue sections (thickness, $4 \mu \mathrm{m}$ ) were dried at $60^{\circ} \mathrm{C}$ for $4 \mathrm{~h}$, and then dewaxed at room temperature with xylene for $10 \mathrm{~min}$, twice. Subsequently, sections were hydrated with gradient alcohol as follows: Absolute ethyl alcohol, room temperature for $1 \mathrm{~min}$, twice; ethyl alcohol (95\%), room temperature for $1 \mathrm{~min}$, twice; ethyl alcohol (80\%), room temperature for $1 \mathrm{~min}$; ethyl alcohol (70\%), room temperature for $1 \mathrm{~min}$; and $\mathrm{dd}_{2} \mathrm{O}$, room temperature for $1 \mathrm{~min}$, twice. Finally, sections were stained with hematoxylin (room temperature for $5 \mathrm{~min}$ ) and $0.5 \%$ eosin (room temperature for $1 \mathrm{~min}$ ). Images were captured using an Olympus BX53 light microscope (Olympus Corporation) (magnification, x100).

Immunohistochemistry staining. Immunohistological staining was conducted as previously described (41). Briefly, formalin-fixed paraffin-embedded tissue sections underwent antigen retrieval by incubation in boiling citric acid buffer (pH 6.0) for $2 \mathrm{~min}$, and then processed with 3\% hydrogen peroxide for $15 \mathrm{~min}$ at room temperature to quench endogenous hydrogen peroxidase. Subsequently, the sections were blocked with $10 \%$ goat serum blocking fluid (cat. no. ZLI-9021; ZSGB-Bio) for $30 \mathrm{~min}$ at room temperature. The sections were then incubated with anti-TRPM2 rabbit pAb primary antibody (Abcam; cat. no. ab87050; 1:200 dilution) overnight at $4^{\circ} \mathrm{C}$ and then incubated with an EnVision System HRP-Polymer (cat. no. PV-6001; ZSGB-Bio) for $30 \mathrm{~min}$ at room temperature. Finally, all the sections were incubated with a Liquid DAB Substrate Chromogen System (cat. no. ZLI-9019; ZSGB-Bio). All images of the immunohistochemistry staining sections were captured using an Olympus BX53 light microscope (Olympus Corporation) (magnification, x100 or x400).

Western blot analysis. The western blot analysis was conducted as previously described (41). Briefly, tongue tissues were weighed and ground in ice-cold RIPA buffer (Beyotime Institute of Biotechnology; cat. no. P0013B) with 1X PMSF and $1 \mathrm{X}$ protease inhibitor cocktail (Sigma-Aldrich; Merck $\mathrm{KGaA}$; cat. no. P8340), and fully lysed for $30 \mathrm{~min}$. The mixture was then centrifuged at $14,000 \mathrm{x}$ g for $15 \mathrm{~min}$ at $4^{\circ} \mathrm{C}$ to collect the protein supernatant. Subsequently, a BCA protein assay kit (Beyotime Institute of Biotechnology; cat. no. P0009) was used to determine the protein concentrations according to the manufacturer's protocol. A total of $\sim 40 \mu \mathrm{g}$ total protein per lane was subjected to electrophoresis on 8 or $10 \%$ SDS-PAGE. The proteins were then transferred to PVDF membranes (EMD Millipore; cat. no. ISEQ00010), blocked with 5\% Difco ${ }^{\mathrm{TM}}$ Skim Milk (BD Biosciences; cat. no. 232100) in TBST for $2 \mathrm{~h}$ at room temperature and then incubated with the anti-TRPM2 Rabbit pAb (Abcam; cat. no. ab96785; 1:1,000 dilution), anti-caspase-8 rabbit mAb (Abcam; cat. no. ab32397; 1:1,000 dilution), anti-Bcl-xL rabbit mAb (Abcam; cat. no. ab32370; 1:1,000 dilution), anti-Bax rabbit pAb [Cell Signaling Technology (cat. no. 2772; 1:1,000 dilution), anti-caspase-9 rabbit mAb (Abcam; cat. no. ab202068; 1:1,000 dilution), anti-caspase-3 
mouse mAb (Abcam; cat. no. ab13585; 1:1,000 dilution) and anti- $\beta$-actin mouse $\mathrm{mAb}$ (Sigma-Aldrich; Merck KGaA; cat. no. A5316; 1:5,000 dilution)] primary antibodies overnight at $4^{\circ} \mathrm{C}$. The PVDF membranes were then incubated with IRDye $^{\circledR} 800 \mathrm{CW}$ Goat anti-Rabbit IgG (LI-COR Biosciences; cat. no. 926-32211; 1:5,000 dilution) or IRDye ${ }^{\circledR}$ 680LT Goat anti-Mouse IgG (LI-COR Biosciences; cat. no. 926-68020; 1:5,000 dilution) for $1 \mathrm{~h}$. Finally, an Odyssey Infrared Imaging System (LI-COR Biosciences) was used to visualize protein bands and Image Studio Lite Ver 4.0 software (LI-COR Biosciences) was used for densitometric analysis.

Reverse transcription-quantitative (RT-q)PCR. Total RNA was extracted from 26 clinical patient samples using RNAiso Plus (Takara Bio., Inc.; cat. no. 9109). cDNA was synthesized from $1 \mu \mathrm{g}$ total RNA by using PrimeScript ${ }^{\mathrm{TM}} \mathrm{RT}$ reagent Kit with gDNA Eraser (Takara Bio., Inc.; cat. no. RR047A). qPCR was performed using TB Green ${ }^{\mathrm{TM}}$ Premix Ex Taq ${ }^{\mathrm{TM}}$ II kit (Takara Bio., Inc.; cat. no. RR820A) on an ABI 7500 Fast Real-time fluorescence quantitative PCR system (Thermo Fisher Scientific, Inc.). RT-qPCR was performed as follows: Initial denaturation, $95^{\circ} \mathrm{C}, 30 \mathrm{sec}$; cycling stage, denaturation, $95^{\circ} \mathrm{C}, 3 \mathrm{sec}$ and annealing, $60^{\circ} \mathrm{C}, 30 \mathrm{sec}(40 \mathrm{cycles})$; final extension, denaturation, $95^{\circ} \mathrm{C}, 15 \mathrm{sec}$, annealing, $60^{\circ} \mathrm{C}, 1 \mathrm{~min}$ and elongation, $95^{\circ} \mathrm{C}, 15 \mathrm{sec}$. The primers for TRPM2 were as follows: Forward, 5'-TTCGTGGATTCCTGAAAACATCA-3'; and reverse, 5'-CCAGCATCAGACAGTTTGGAAC-3'. The primers for GAPDH were as follows: Forward, 5'-ACAGTC CATGCCATCACTG-3'; and reverse, 5'-AGTAGAGGCAGG GATGATG-3'. GAPDH was used as the internal reference, and the relative expression levels were calculated using the $2^{(-\Delta \Delta \mathrm{Cq})}$ method (42).

Malondialdehyde (MDA) measurement. Tongue tissues were ground and lysed in ice-cold RIPA buffer (Beyotime Institute of Biotechnology; cat. no. P0013B) with 1X PMSF and $1 \mathrm{X}$ protease inhibitor cocktail (Sigma-Aldrich; Merck $\mathrm{KGaA}$; cat. no. P8340). Subsequently, a BCA protein assay kit (Beyotime Institute of Biotechnology; cat. no. P0009) was used to determine the protein concentrations according to the manufacturer's protocol. The Lipid Peroxidation MDA Assay kit (Beyotime Institute of Biotechnology; cat. no. S0131) was used to assay the MDA content following the manufacturer's protocol. The absorption was measured at $532 \mathrm{~nm}$, with the reference wave set at $450 \mathrm{~nm}$. MDA content levels were calculated according to the established standard curve using the reference standards in the kit, calculated under the same experimental conditions, and presented as $\mu \mathrm{mol} / \mathrm{mg}$ protein.

Superoxide dismutase (SOD) activity measurement. A total of $10 \mathrm{mg}$ tongue tissue from each patient was homogenized in $100 \mu 1$ ice-cold SOD sample preparation liquid, and then centrifuged at $14,000 \mathrm{x}$ g for $5 \mathrm{~min}$ at $4^{\circ} \mathrm{C}$. Subsequently, the supernatant was collected and used for measuring the SOD activity using the Total Superoxide Dismutase Assay kit with WST-8 (Beyotime Institute of Biotechnology; cat. no. S0101) following the manufacturer's protocol. The absorption was measured at $450 \mathrm{~nm}$ and the absorption of the reference wave was set at $630 \mathrm{~nm}$. The SOD activity was normalized to protein levels and presented as $\mathrm{U} / \mathrm{mg}$ protein.
Table I. Expression levels of TRPM2 and its association with clinical pathological characteristics.

\begin{tabular}{lrrrr}
\hline & \multicolumn{4}{c}{ TRPM2 } \\
& \multicolumn{4}{c}{ expression levels } \\
$\begin{array}{l}\text { Clinical } \\
\text { characteristics }\end{array}$ & $\begin{array}{c}\text { Cases } \\
(\mathrm{n}=26)\end{array}$ & $\begin{array}{c}\text { Low } \\
(\mathrm{n}=14)\end{array}$ & $\begin{array}{c}\text { High } \\
(\mathrm{n}=12)\end{array}$ & P-value \\
\hline Sex & & & & \\
$\quad$ Male & 17 & 11 & 6 & 0.218 \\
Female & 9 & 3 & 6 & \\
Age, years & & & & \\
$<50$ & 10 & 6 & 4 & 0.701 \\
$\geq 50$ & 16 & 8 & 8 & \\
Lymph node metastasis & & & & \\
$\quad$ Yes & 12 & 7 & 5 & 0.713 \\
$\quad$ No & 14 & 7 & 7 & \\
Differentiation degree & & & & \\
Moderate or poor & 17 & 13 & 4 & $0.003^{\mathrm{a}}$ \\
$\quad$ Well & 9 & 1 & 8 & \\
TNM stage & & & & \\
T1 & 9 & 5 & 4 & 0.810 \\
T2 & 14 & 7 & 7 & \\
T3 & 2 & 1 & 1 & \\
T4 & 1 & 1 & 0 & \\
\hline
\end{tabular}

${ }^{\mathrm{a}} \mathrm{P}<0.01$. TRPM2, transient receptor potential melastatin 2 .

Statistical analysis. All data are presented as the mean \pm SEM. Each experiment was repeated at least 3 times. The statistical analysis was performed using one-way ANOVA followed by Tukey's post hoc test for comparison between groups, and $\mathrm{P}<0.05$ was considered to indicate a statistically significant difference. Associations between the expression levels of TRPM2 and clinical pathological characteristics were evaluated by Fisher's exact test. GraphPad Prism 6 software (GraphPad Software, Inc.) was used for all statistical analyses.

\section{Results}

TRPM2 expression level is associated with TSCC differentiation degree. The TRPM 2 protein and mRNA expression levels in normal tongue tissue $(\mathrm{N})$, peritumor tissue (P) and TSCC tissue (T) of 26 patients with TSCC were analyzed by western blot analysis and qPCR. Notably, the expression of TRPM2 varied greatly among patients. The statistical analysis results indicated that there was no significant difference in TRPM 2 protein and mRNA expression levels between the $\mathrm{P}, \mathrm{T}$ and $\mathrm{N}$ tongue tissues (Fig. 1A-C). By analyzing the association between the expression level of TRPM 2 channel and the clinical pathological characteristics of the patients, it was identified that the expression level of TRPM2 was only significantly associated TSCC tumor differentiation degree (Table I). Therefore, the patients with TSCC were divided into well-, moderately, or poorly differentiated groups, as demonstrated in Fig. 1D-H. The mRNA and protein expression levels of TRPM2 were increased in the tumor tissues in 
A

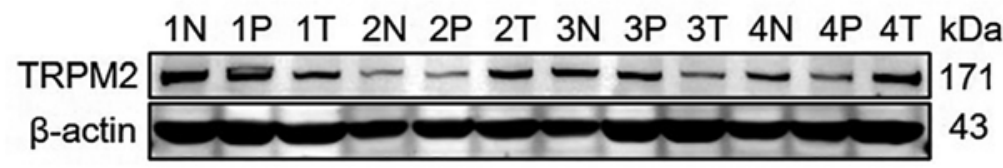

$5 \mathrm{~N} \quad 5 \mathrm{P} \quad 5 \mathrm{~T} \quad 6 \mathrm{~N} \quad 6 \mathrm{P} \quad 6 \mathrm{~T} \quad 7 \mathrm{~N} \quad 7 \mathrm{P} \quad 7 \mathrm{~T} \quad 8 \mathrm{~N} \quad 8 \mathrm{P} \quad 8 \mathrm{~T}$

TRPM2 $-\ldots 171$

$\beta$-actin 43

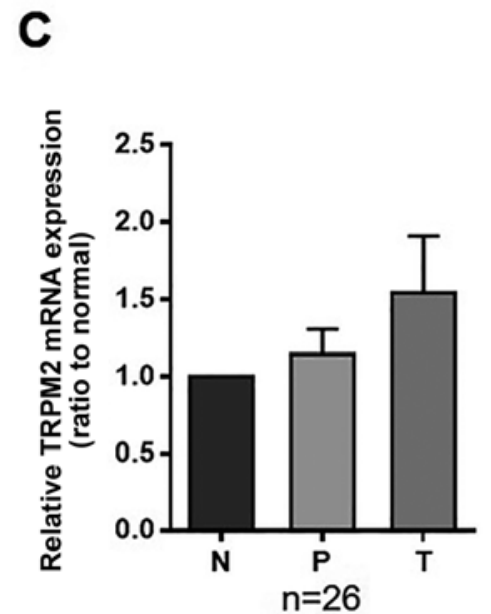

D

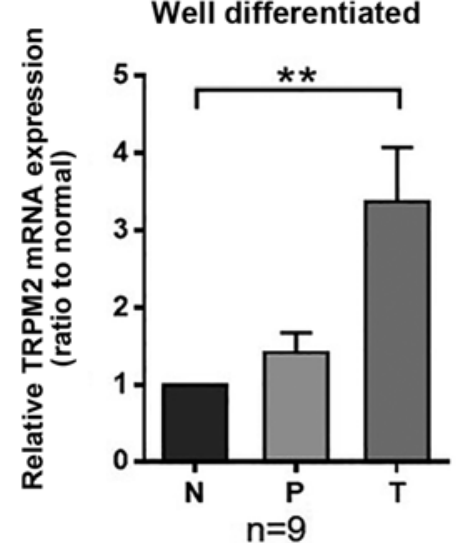

$\mathbf{F}$

Well differentiated

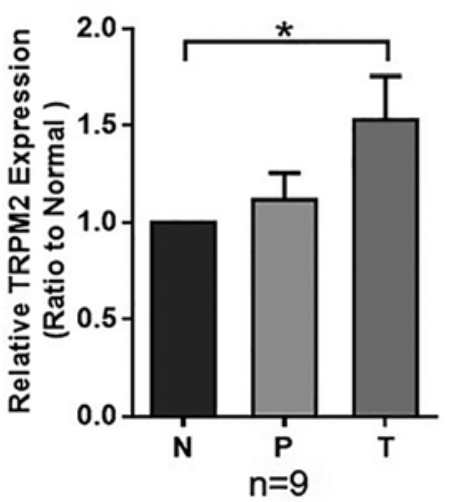

B

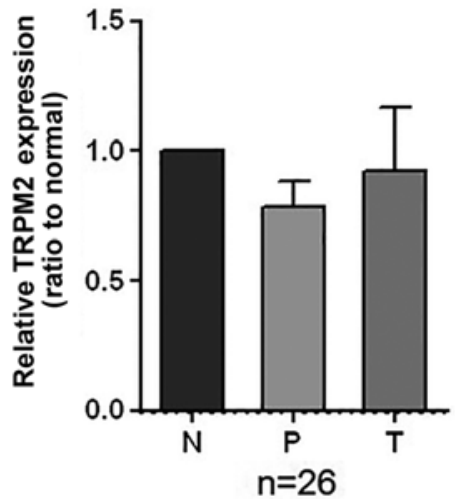

E

Moderate or poor differentiated

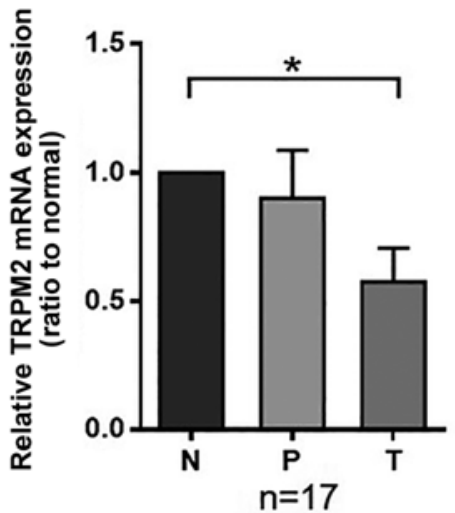

H
Well differentiated

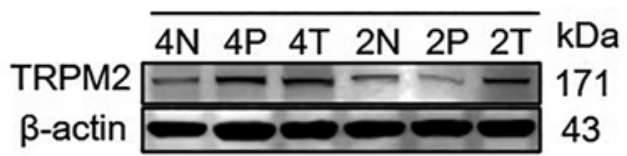

Moderate or poor differentiated

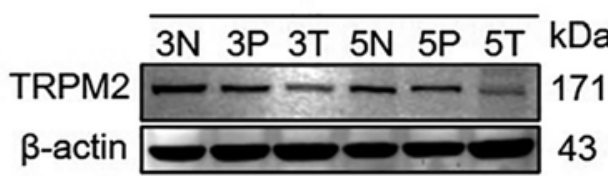

Figure 1. TRPM2 expression level is associated with TSCC differentiation degree. (A) The expression levels of the TRPM2 channel in N, P, and T groups of 26 patients with TSCC were detected by western blot analysis. (B) No significant difference was observed in peritumor and tumor tissues, compared with normal tongue tissue $(n=26)$. All data were normalized with normal tongue tissue and are presented as the mean \pm SEM. $(C)$ The expression levels of TRPM2 mRNA in N, P, and T groups of the 26 patients with TSCC were detected by qPCR. There was no significant difference among the three groups observed ( T vs. N; $\mathrm{P}=0.1798$ ). (D) Statistical analysis of the relative TRPM2 mRNA expression levels in well-differentiated tumor tissues ( $\mathrm{n}=9$ ). ${ }^{* *} \mathrm{P}<0.01$. (E) Statistical analysis of relative TRPM2 mRNA expression levels in moderately or poorly differentiated tissues ( $\mathrm{n}=17)$. * $\mathrm{P}<0.05$. (F) Statistical analysis of the TRPM2 protein expression levels in well-differentiated tumor tissues $(n=9)$. $P<0.05$. (G) Statistical analysis of protein expression of TRPM2 in moderate or poorly differentiated tissues $(\mathrm{n}=17) .{ }^{* *} \mathrm{P}<0.05 \mathrm{e}$. $(\mathrm{H})$ Representative image of western blot analysis gel demonstrates that TRPM2 expression was upregulated in the well-differentiated tumor tissues, while significantly downregulated in the moderately or poorly differentiated groups. TRPM2, transient receptor potential melastatin 2; TSCC, tongue squamous cell carcinoma; N, normal tongue tissues; P, peritumor tissues; T, tongue squamous cell carcinoma tissues.

the well-differentiated tumor group (Fig. 1D, F and H). By contrast, TRPM2 expression was significantly decreased in the tissues in the moderately and poorly differentiated groups (Fig. 1E, G and H). Immunohistochemical analysis demonstrated similar results (Fig. 2). These data suggested that the protein expression levels of TRPM 2 in the TSCC tissues were associated with different degrees of tumor differentiation.
Oxidative stress levels are significantly increased in tissues with low TRPM2 expression. TRPM2 is a typical cationic channel sensitive to oxidative stress, and it can be activated by external stimuli such as ROS, thereby regulating the survival or death of tumor cells. In order to clarify the association between oxidative stress level and differential expression of TRPM2 proteins in the TSCC tissues, the content of MDA, 


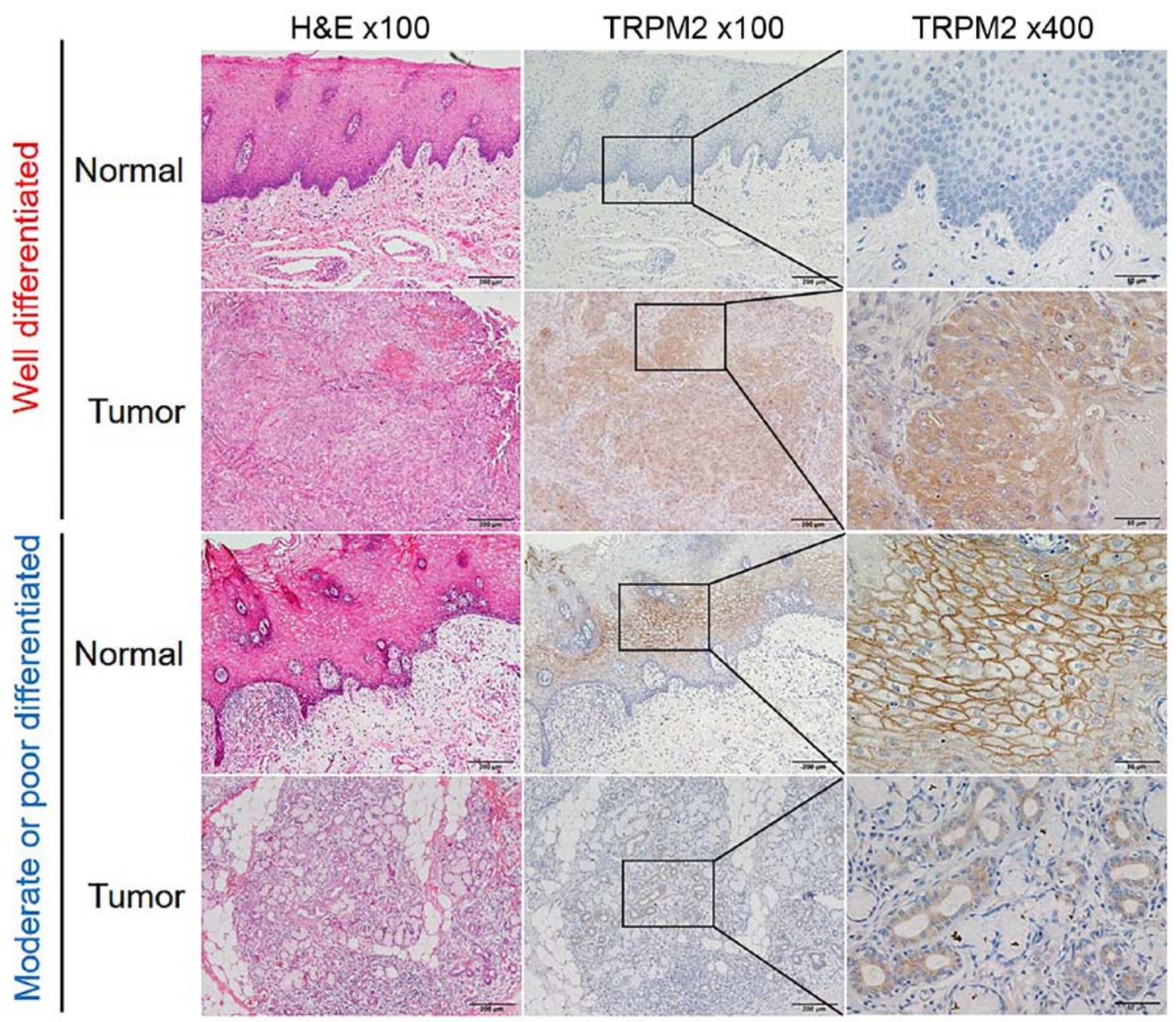

Figure 2. TRPM2 expression is significantly upregulated in well-differentiated TSCC tissues, and downregulated in moderately or poorly differentiated TSCC tumors. Representative image of immunohistochemical staining of TRPM2 in tongue tissue specimens. Scale bars=200 (left-hand and middle columns) or $50 \mu \mathrm{m}$ (right-hand column). TRPM2, transient receptor potential melastatin 2.

a key indicator of oxidative stress, and the enzyme activity level of antioxidant enzyme SOD were detected in tissues with high and low TRPM2 expression. As indicated in Fig. 3A-D, no significant differences in MDA content and SOD enzyme activity were identified in tumor tissues in the high TRPM2 expression group as compared with the normal and peritumor tissues. By contrast, significantly increased MDA content and decreased activity of antioxidant enzyme SOD were detected in tissues with low TRPM2 expression, indicating that the oxidative stress level was significantly increased in this group.

Apoptosis levels are significantly increased in tissues with low TRPM2 expression. Moderate level of oxidative stress can modulate cellular survival and metabolic pathways to enhance cell proliferation. However, as the oxidative stress level rises, it damages tissues through protein oxidation, lipid peroxidation, DNA oxidation and mutagenesis, and activation of cell death pathways (7). As apoptosis is one of the most common forms of cell death, the expression of apoptosis-associated proteins in TSCC tissues with high and low TRPM2 expression levels were explored. As shown in Fig. 4C and D, the expression level of anti-apoptotic protein Bcl-xL was significantly downregulated in the tissues with low TRPM2 expression levels.
By contrast, the expression levels of pro-apoptotic proteins including Caspase-8, Bax, and the cleaved form of caspase-9, caspase-3, and poly [ADP-ribose] polymerase (PARP) were significantly increased, suggesting a significant increase in the apoptosis level in this group. However, no significant increase in the expression levels of these pro-apoptotic proteins was detected in the high TRPM2 expression group (Fig. 4A and B). Taken together with the data regarding the oxidative stress levels in each group, we hypothesize that downregulation of the TRPM2 channel may inhibit the ability of cells to adapt to or resist the oxidative stress, increasing their susceptibility to apoptosis.

\section{Discussion}

In the present study, it was determined that the expression level of TRPM2 channel was associated with TSCC differentiation degree by using western blot analysis, qPCR and IHC analyses of tumor, peritumor and normal tissues from patients with TSCC. Notably, the mRNA and protein expression levels of TRPM2 were significantly upregulated in the well-differentiated TSCC tissues, while the opposite result was observed in the moderately or poorly differentiated TSCC tissues. 


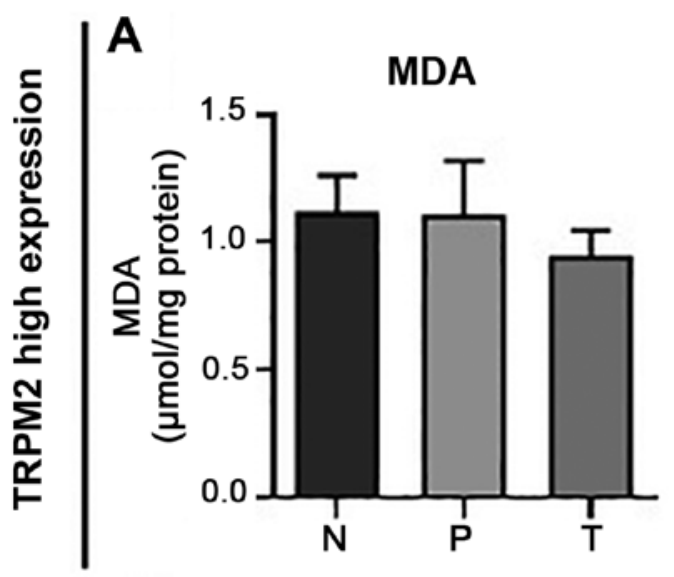

B
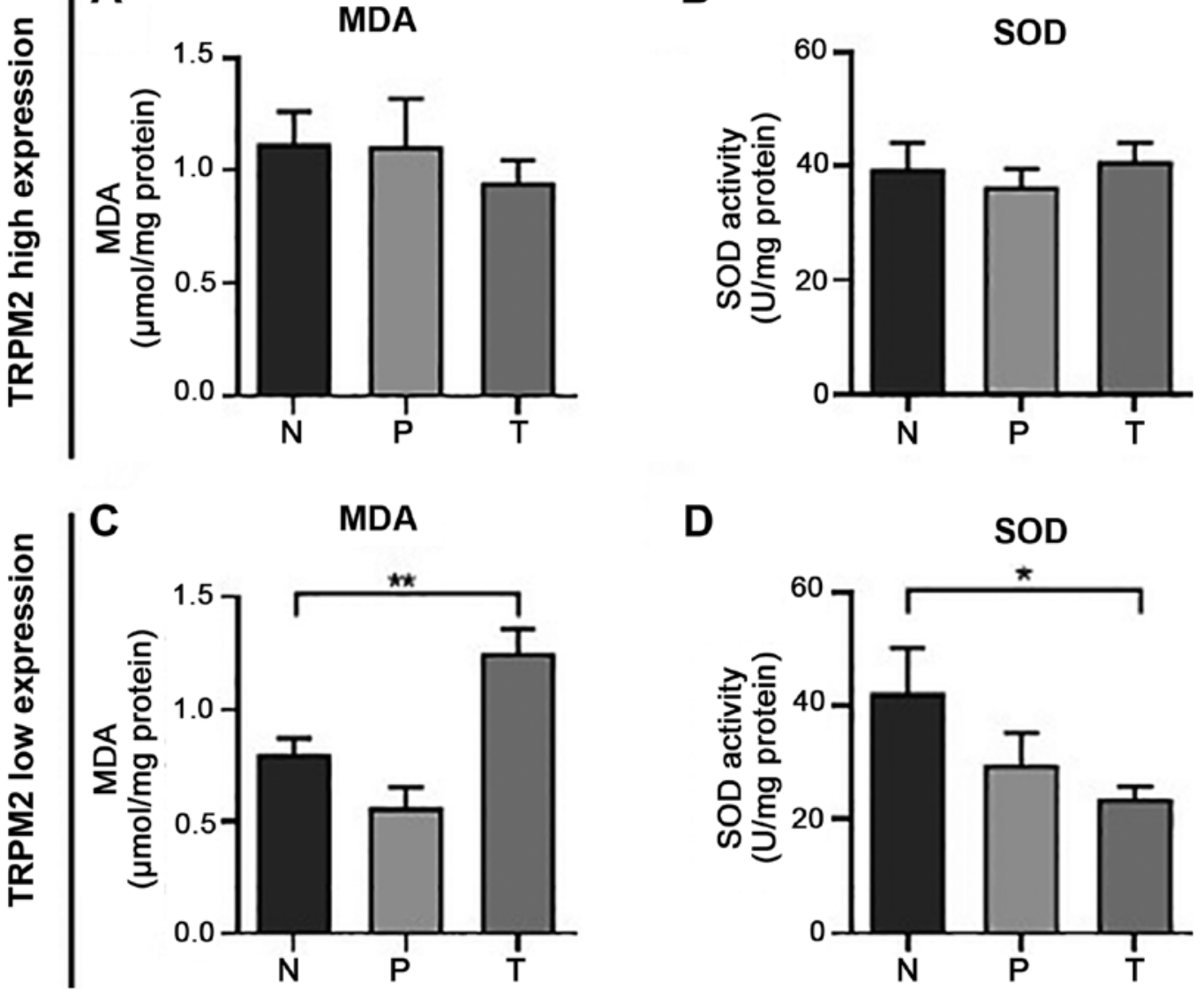

D

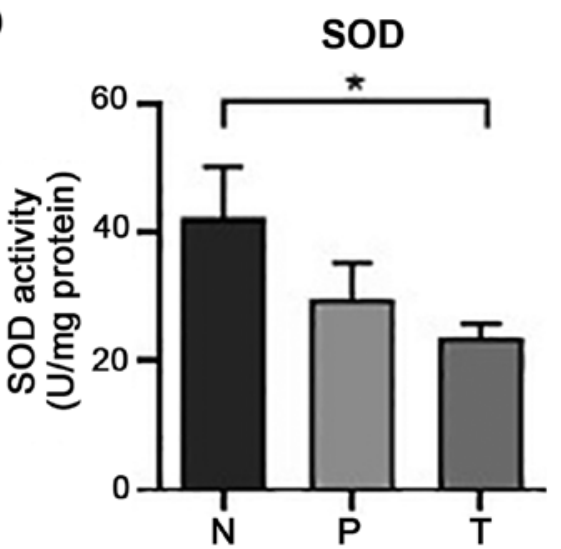

Figure 3. Oxidative stress level is significantly increased in tissues with low TRPM2 expression. (A and B) The (A) MDA content and (B) SOD activity in high TRPM2 expressed tumor tissues in the well-differentiated tumor group $(\mathrm{n}=5)$. (C and $\mathrm{D})$ The (C) MDA content and (D) SOD activity in low TRPM2 expressed tumor tissues in the moderately or poorly differentiated group $(n=5)$. Each experiment was repeated 3 times with duplicate samples and data are presented as the mean \pm SEM. ${ }^{*} \mathrm{P}<0.05$ and ${ }^{* *} \mathrm{P}<0.01$. TRPM2, transient receptor potential melastatin 2 ; $\mathrm{N}$, normal tongue tissues; $\mathrm{P}$, peritumor tissues; $\mathrm{T}$, tongue squamous cell carcinoma tissues; MDA, malondialdehyde; SOD, superoxide dismutase.

The TRPM2 channel has been implicated as an oxidative stress sensor in a number of physiological and pathological processes $(7,43,44)$. It has been demonstrated that normal physiological levels of ROS can activate transcription factors and signaling kinases, but excessive increases in ROS result in damage to mitochondria, DNA, proteins and lipids, thus leading to cell death (7). However, a large volume of evidence suggests that malignant cells increase their antioxidant capacities to prevent tissue damage when ROS levels are increased $(12,45)$. Therefore, it is important to determine the oxidative stress levels in TSCC tissues, to further understand the function of TRPM2 channel in the modulation of oxidative stress in TSCC. MDA is one of the most important indicators used to reflect the oxidative stress levels of cells or tissues, while SOD is an efficient and powerful antioxidant enzyme that acts to decrease the levels of oxidative stress in an organism $(2,46)$. By detecting the content of MDA and activity of SOD, the present study identified that in the TSCC tissues with low TRPM2 expression, the MDA content was significantly increased and the SOD activity was decreased significantly compared with normal tongue tissues, which is consistent with the results reported by Bao et al (12), which demonstrated that TRPM2 knockout significantly decreased the expression of antioxidant enzyme SOD2 under doxorubicin-induced oxidative stress in the neuroblastoma SH-SY5Y cell line, indicating that a low expression of TRPM2 was associated with a higher level of oxidative stress. This observation has also been confirmed by other studies, in which the inhibition or downregulation of TRPM2 expression significantly increased the production of intracellular ROS in response to oxidative stress, leading to mitochondrial dysfunction, DNA damage, apoptosis and cell death $(7,10,12,30,35,39,40)$. Furthermore, considering the association between the expression level of TRPM 2 and the differentiation degree of TSCC, we hypothesize that the poorly differentiated tissues exhibit a decreased TRPM2 expression level but an increased level of oxidative stress. It has been reported that the degree of tumor differentiation is associated with the level of oxidative stress. For example, it was observed in patients with breast cancer that the expression levels of cytochrome P450 1A1 and cytochrome P450 1B1, 2 oxidative stress markers, were significantly higher in grade III (poorly differentiated) tumors as compared with patients with grades I (well-differentiated) and II (moderately differentiated) tumors (47). This is consistent with the observation of the present study that the poorly differentiated tissues exhibited an increased level of oxidative stress.

As TRPM2 is sensitive to oxidative stress, we hypothesize that TRPM2 serves an important role in regulating the oxidative stress level of TSCC tissues and determining cell fate. The present study identified a significant increase 
A

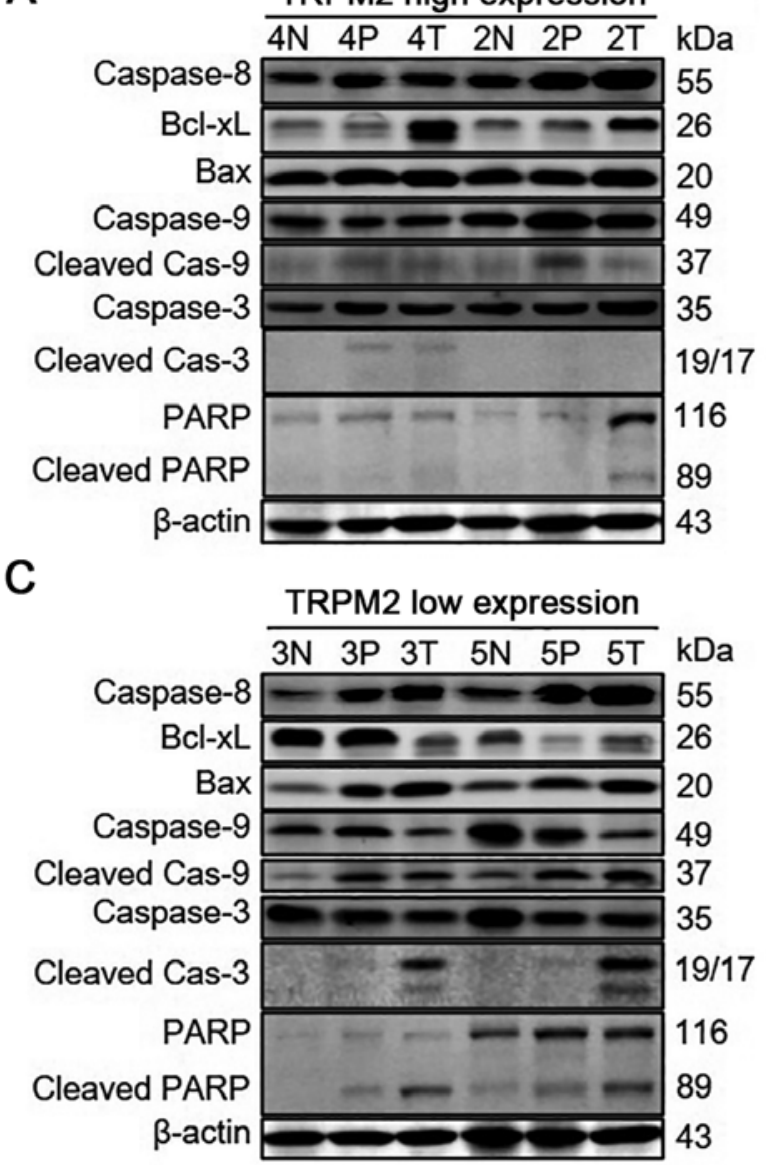

B
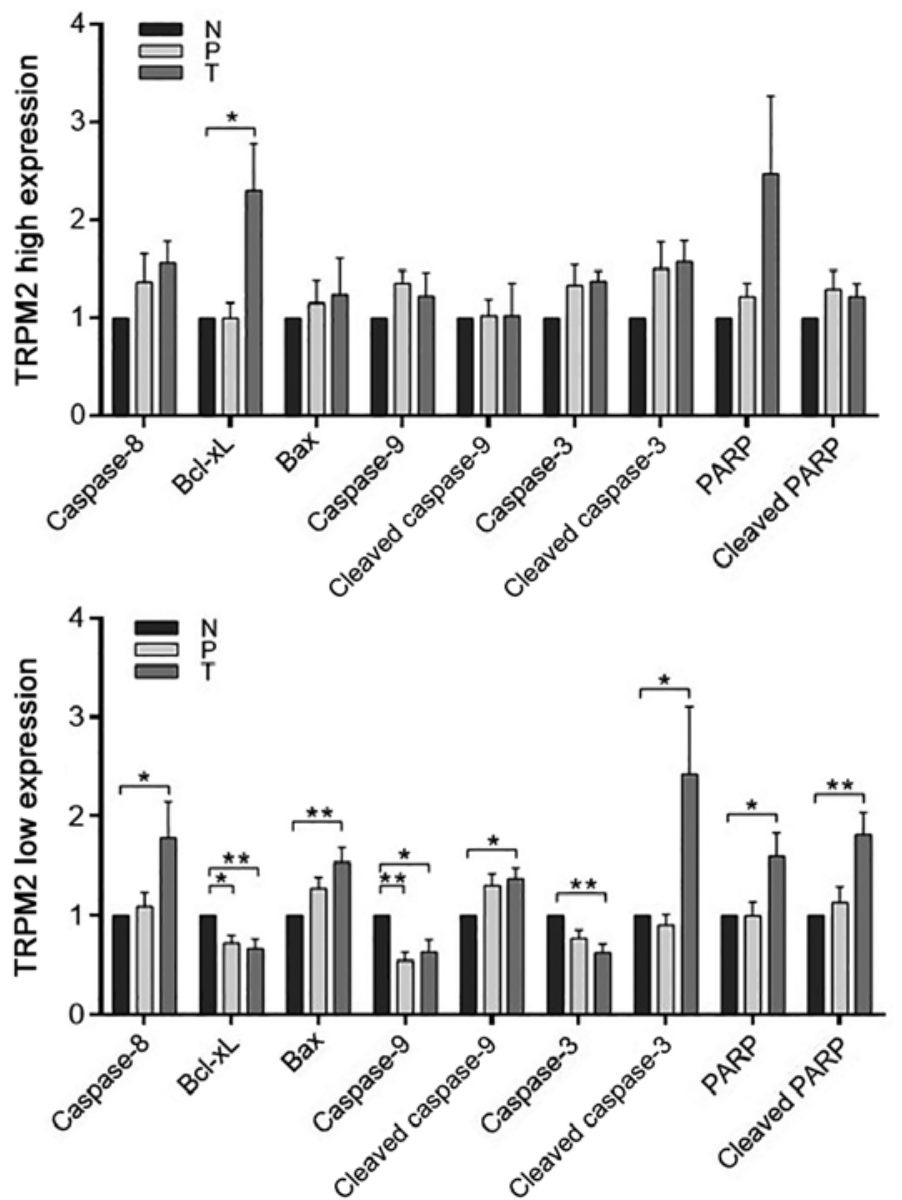

Figure 4. Apoptosis is significantly increased in tissues with low TRPM2 expression. (A and C) Western blotting analysis was used to explore the expression of apoptosis-associated proteins (caspase-8, Bcl-xL, Bax, caspase-9, cleaved caspase-9, caspase-3, cleaved caspase-3, PARP, cleaved PARP) in TSCC tissues with (A) high or (C) low TRPM2 expression in the N, P, and T groups. $\beta$-actin was used as a loading control. (B and D) Statistical analysis of the expression levels of the apoptosis-associated proteins (caspase-8, Bcl-xL, Bax, caspase-9, cleaved caspase-9, caspase-3, cleaved caspase-3, PARP, cleaved PARP) with (B) high or (D) low TRPM2 expression in the N, P, and T groups. All data were normalized to the data from the normal tongue tissue and presented as the mean \pm SEM. ${ }^{*} \mathrm{P}<0.05$ and ${ }^{* *} \mathrm{P}<0.01$. TRPM2, transient receptor potential melastatin 2 ; TSCC, tongue squamous cell carcinoma; $\mathrm{N}$, normal tongue tissues; $\mathrm{P}$, peritumor tissues; T, tongue squamous cell carcinoma tissues; PARP, poly [ADP-ribose] polymerase.

in apoptosis levels in the TSCC tissues with low TRPM2 expression, suggesting that the expression level of the TRPM2 channel is associated with apoptosis. These results have been supported by Bao et al (10), who observed that depletion of TRPM 2 resulted in increased mitochondrial ROS and enhanced apoptosis in neuroblastoma cells when treated with chemotherapeutic agents such as doxorubicin. All of these results also explain the situation commonly encountered in the clinical treatment of tumors, in which patients with poorly differentiated carcinoma exhibit increased sensitivity to chemotherapy drugs, suggesting that poorly differentiated tumor cells are more susceptible to chemotherapy-induced apoptosis. Similarly, a more recent study has also shown that downregulation of TRPM2 significantly inhibited cell proliferation and promoted apoptosis via increasing intracellular ROS and RNS levels and activating the JNK pathway in lung cancer cells (18). In addition, regarding the association between differentiation degree and apoptosis level, it was reported that in a poorly differentiated Mahlavu cell subline, the overproduction of ROS resulted in a significant decrease in mitochondrial transmembrane potential and activated caspases-3/7, resulting in increased apoptosis (48). These results are consistent with the results of the present study, which demonstrated that the expression levels of cleaved caspase- 9 and cleaved caspase-3 were significantly increased in poorly differentiated TSCC tissues with low TRPM2 expression, suggesting an increase in the levels of apoptosis in these tissues. In addition, the expression levels of anti-apoptotic protein Bcl-xL and pro-apoptotic protein Bax were also detected. Bcl-xL was significantly downregulated in the TSCC tissues with low TRPM2 expression, while Bax was upregulated in this group. A previous study reported a similar result, demonstrating that $\mathrm{Bcl}-\mathrm{xL}$ genes expression level was positively associated with the degree of differentiation and the clinical TNM staging (49). Taken together, we hypothesize that the low expression of the TRPM 2 channel observed in the moderately and poorly differentiated TSCC inhibited the ability of cells to cope with oxidative stress injury, resulting in an increased level of apoptosis. The data from the present study also suggest that inhibition of TRPM2 functional expression may represent a potential therapeutic strategy for patients with TSCC, by promoting tumor cell apoptosis. 
However, considering the varying expression levels of TRPM2 channel observed in different types of differentiated tumor tissues, the specific molecular regulatory mechanism, and the effectiveness of TRPM2 inhibitors for patients with TSCC with distinct tumor differentiation levels remain unknown, and will explored in future studies.

In conclusion, the present study provides the first clinical evidence that the expression levels of TRPM2 channel were associated with TSCC differentiation degree. The association between TRPM2 expression, oxidative stress level, apoptosis level and the degree of cell differentiation were established, which may lead to the identification a potent biomarker for tumor cell differentiation and provide insights into the mechanisms in TSCC pathogenesis.

\section{Acknowledgements}

The authors thank Dr Yiquan Tang (Medical Research Council Laboratory of Molecular Biology, Cambridge, UK) for their comments and revision of the manuscript.

\section{Funding}

The authors gratefully acknowledge financial support from Zhejiang Provincial Natural Science Foundation (grant no. LY19B020013), and Applied Research Program for Public Welfare Technology of Zhejiang Province (grant no. 2017C33017).

\section{Availability of data and materials}

The datasets used and/or analyzed during the current study are available from the corresponding author on reasonable request.

\section{Authors' contributions}

FZ and XC performed the experiments, analyzed, and interpreted the data, and wrote the manuscript. XY, JH, CW, MW and AS collected the samples, and analyzed and interpreted the data. PY, WY and XZ conceptualized the study, designed the experiments and critically revised the manuscript. All authors have full access to all the data in the study and take responsibility for the integrity and security of the data. All authors read and approved the final manuscript.

\section{Ethics approval and consent to participate}

The study protocol conformed to the ethical standards outlined in the Declaration of Helsinki of 1975, as revised in 2008 and ethical approval was obtained from the Zhejiang University School of Medicine Ethics Committee, and written informed consent was obtained from each patient. All study subjects were fully informed of the study protocol and procedures prior to participating in the study.

\section{Patient consent for publication}

Written informed consent for the publication of clinical data and accompanying images was obtained from the patient, patient's guardian or next of kin prior to the study.

\section{Competing interests}

The authors declare that they have no competing interests.

\section{References}

1. Bray F, Ferlay J, Soerjomataram I, Siegel R, Torre L and Jemal A: Global cancer statistics 2018: GLOBOCAN estimates of incidence and mortality worldwide for 36 cancers in 185 countries. CA Cancer J Clin 68: 394-424, 2018.

2. Yokoe H, Nomura H, Yamano Y, Fushimi K, Sakamoto Y, Ogawara K, Shiiba M, Bukawa H, Uzawa K, Takiguchi Y and Tanzawa H: Alteration of extracellular superoxide dismutase expression is associated with an aggressive phenotype of oral squamous-cell carcinoma. Exp Ther Med 1: 585-590, 2010.

3. Bello I, Soini Y and Salo T: Prognostic evaluation of oral tongue cancer: Means, markers and perspectives (II). Oral Oncol 46: 636-643, 2010.

4. El-Naggar AK, Chan JKC, Grandis JR, Takata T and Slootweg PJ (eds): WHO classification of head and neck tumours. World Health Orgn, Lyon, IARC Press, pp160, 2017.

5. Jiang LH, Yang W, Zou J and Beech DJ: TRPM2 channel properties, functions and therapeutic potentials. Expert Opin Ther Targets 14: 973-988, 2010.

6. Ru X and Yao X: TRPM2: A multifunctional ion channel for oxidative stress sensing. Sheng Li Xue Bao 66: 7-15, 2014.

7. Miller B: TRPM2 in cancer. Cell Calcium 80: 8-17, 2019.

8. Zhang W, Chu X, Tong Q, Cheung JY, Conrad K, Masker K and Miller BA: A novel TRPM2 isoform inhibits calcium influx and susceptibility to cell death. J Biol Chem 278: 16222-16229, 2003.

9. Chen SJ, Hoffman NE, Shanmughapriya S, Bao L, Keefer K, Conrad K, Merali S, Takahashi Y, Abraham T, Hirschler-Laszkiewicz I, et al: A splice variant of the human ion channel TRPM2 modulates neuroblastoma tumor growth through hypoxia-inducible factor (HIF)-1/2 $\alpha$. J Biol Chem 289: 36284-36302, 2014.

10. Bao L, Chen SJ, Conrad K, Keefer K, Abraham T, Lee JP, Wang J, Zhang XQ, Hirschler-Laszkiewicz I, Wang HG, et al: Depletion of the human ion channel TRPM2 in neuroblastoma demonstrates its key role in cell survival through modulation of mitochondrial reactive oxygen species and bioenergetics. J Biol Chem 291: 24449-24464, 2016

11. Hirschler-Laszkiewicz I, Chen SJ, Bao L, Wang J, Zhang XQ, Shanmughapriya S, Keefer K, Madesh M, Cheung JY and Miller BA: The human ion channel TRPM2 modulates neuroblastoma cell survival and mitochondrial function through Pyk2, CREB, and MCU activation. Am J Physiol Cell Physiol 315: C571-C586, 2018.

12. Bao L, Festa F, Freet CS, Lee JP, Hirschler-Laszkiewicz IM, Chen SJ, Keefer KA, Wang HG, Patterson AD, Cheung JY and Miller BA: The human transient receptor potential melastatin 2 ion channel modulates ROS through Nrf2. Sci Rep 9: 14132, 2019.

13. Ishii M, Oyama A, Hagiwara T, Miyazaki A, Mori Y, Kiuchi Y and Shimizu S: Facilitation of H2O2-induced A172 human glioblastoma cell death by insertion of oxidative stress-sensitive TRPM2 channels. Anticancer Res 27: 3987-3992, 2007.

14. Ertilav K, Nazıroğlu M, Ataizi ZS and Braidy N: Selenium enhances the apoptotic efficacy of docetaxel through activation of TRPM2 channel in DBTRG glioblastoma cells. Neurotox Res 35: 797-808, 2019.

15. Ma LY, Xie XW, Ma L, Pang JL, Xiong XM, Zheng HD, Shen XL, Wen ZG and Wang HY: Downregulated long non-coding RNA TRPM2-AS inhibits cisplatin resistance of non-small cell lung cancer cells via activation of p53-p66shc pathway. Eur Rev Med Pharmacol Sci 21: 2626-2634, 2017.

16. Huang C, Qin Y, Liu H, Liang N, Chen Y, Ma D, Han Z, Xu X, Zhou X, He J and Li S: Downregulation of a novel long noncoding RNA TRPM2-AS promotes apoptosis in non-small cell lung cancer. Tumour Biol 39: 1010428317691191, 2017.

17. Masumoto K, Tsukimoto M and Kojima S: Role of TRPM2 and TRPV1 cation channels in cellular responses to radiation-induced DNA damage. Biochim Biophys Acta 1830: 3382-3390, 2013.

18. Almasi S, Long CY, Sterea A, Clements DR, Gujar S and Hiani YE: TRPM2 silencing causes G2/M arrest and apoptosis in lung cancer cells via increasing intracellular ROS and RNS levels and activating the JNK pathway. Cell Physiol Biochem 52: 742-757, 2019. 
19. Orfanelli U, Wenke AK, Doglioni C, Russo V, Bosserhoff AK and Lavorgna G: Identification of novel sense and antisense transcription at the TRPM2 locus in cancer. Cell Res 18: 1128-1140, 2008.

20. Guo H, Carlson JA and Slominski A: Role of TRPM in melanocytes and melanoma. Exp Dermatol 21: 650-654, 2012.

21. Homma Y, Nomiya A, Tagaya M, Oyama T, Takagaki K, Nishimatsu $\mathrm{H}$ and Igawa $\mathrm{Y}$ : Increased mRNA expression of genes involved in pronociceptive inflammatory reactions in bladder tissue of interstitial cystitis. J Urol 190: 1925-1931, 2013.

22. Ceylan GG, Önalan EE, Kuloğlu T, Aydoğ G, Keleş İ, Tonyali Ş and Ceylan C: Potential role of melastatin-related transient receptor potential cation channel subfamily $\mathrm{M}$ gene expression in the pathogenesis of urinary bladder cancer. Oncol Lett 12: 5235-5239, 2016

23. Cao QF, Qian SB, Wang N, Zhang L, Wang WM and Shen HB: TRPM2 mediates histone deacetylase inhibition-induced apoptosis in bladder cancer cells. Cancer Biother Radiopharm 30: 87-93, 2015.

24. Orfanelli U, Jachetti E, Chiacchiera F, Grioni M, Brambilla P, Briganti A, Freschi M, Martinelli-Boneschi F, Doglioni C, Montorsi F, et al: Antisense transcription at the TRPM2 locus as a novel prognostic marker and therapeutic target in prostate cancer. Oncogene 34: 2094-2102, 2015.

25. Mouraviev V, Lee B, Patel V, Albala D, Johansen TE, Partin A, Ross A and Perera RJ: Clinical prospects of long noncoding RNAs as novel biomarkers and therapeutic targets in prostate cancer. Prostate Cancer Prostatic Dis 19: 14-20, 2016.

26. Lavorgna G, Chiacchiera F, Briganti A, Montorsi F, Pasini D and Salonia A: Expression-profiling of apoptosis induced by ablation of the long ncRNA TRPM2-AS in prostate cancer cell. Genom Data 3: 4-5, 2014.

27. Zeng $X$, Sikka SC, Huang L, Sun C, Xu C, Jia D, Abdel-Mageed AB, Pottle JE, Taylor JT and Li M: Novel role for the transient receptor potential channel TRPM2 in prostate cancer cell proliferation. Prostate Cancer Prostatic Dis 13: 195-201, 2010.

28. Koh DW, Powell DP, Blake SD, Hoffman JL, Hopkins MM and Feng X: Enhanced cytotoxicity in triple-negative and estrogen receptor-positive breast adenocarcinoma cells due to inhibition of the transient receptor potential melastatin-2 channel. Oncol Rep 34: 1589-1598, 2015.

29. Sumoza-Toledo A,Espinoza-Gabriel MI and Montiel-Condado D Evaluation of the TRPM2 channel as a biomarker in breast cancer using public databases analysis. Bol Med Hosp Infant Mex 73: 397-404, 2016

30. Hopkins MM, Feng X, Liu M, Parker LP and Koh DW: Inhibition of the transient receptor potential melastatin-2 channel causes increased DNA damage and decreased proliferation in breast adenocarcinoma cells. Int J Oncol 46: 2267-2276, 2015.

31. Guler Y and Ovey IS: Synergic and comparative effect of 5-fluorouracil and leucoverin on breast and colon cancer cells through TRPM2 channels. Bratisl Lek Listy 119: 692-700, 2018

32. Huang B, Chang C, Wang BL and Li H: ELK1-induced upregulation of lncRNA TRPM2-AS promotes tumor progression in gastric cancer by regulating $\mathrm{miR}-195 / \mathrm{HMGA} 1$ axis. J Cell Biochem 120: 16921-16933, 2019.

33. Sterea AM, Egom EE and El Hiani Y: TRP channels in gastric cancer: New hopes and clinical perspectives. Cell Calcium 82: 102053, 2019.

34. Almasi S, Sterea AM, Fernando W, Clements DR, Marcato P, Hoskin DW, Gujar S and El Hiani Y: TRPM2 ion channel promotes gastric cancer migration, invasion and tumor growth through the AKT signaling pathway. Sci Rep 9: 4182, 2019.
35. Almasi S, Kennedy BE, El-Aghil M, Sterea AM, Gujar S, Partida-Sánchez S and El Hiani Y: TRPM2 channel-mediated regulation of autophagy maintains mitochondrial function and promotes gastric cancer cell survival via the JNK-signaling pathway. J Biol Chem 293: 3637-3650, 2018.

36. Bauer I, Grozio A, Lasigliè D, Basile G, Sturla L, Magnone M, Sociali G, Soncini D, Caffa I,Poggi A, et al: The NAD+-dependent histone deacetylase SIRT6 promotes cytokine production and migration in pancreatic cancer cells by regulating $\mathrm{Ca} 2+$ responses. J Biol Chem 287: 40924-40937, 2012.

37. Lin R, Wang Y, Chen Q, Liu Z, Xiao S, Wang B and Shi B: TRPM2 promotes the proliferation and invasion of pancreatic ductal adenocarcinoma. Mol Med Rep 17: 7537-7544, 2018.

38. Yalçın E, Pala Ş, Atılgan R, Kuloğlu T, Önalan E, Artaş G and Buran İ: Is there any difference between endometrial hyperplasia and endometrial carcinoma in terms of expression of TRPM2 and TRPM7 ion channels? Turk J Med Sci 49: 653-660, 2019.

39. Klumpp D, Misovic M, Szteyn K, Shumilina E, Rudner J and Huber SM: Targeting TRPM2 channels impairs radiation-induced cell cycle arrest and fosters cell death of T cell leukemia cells in a Bcl-2-dependent manner. Oxid Med Cell Longev 2016: 8026702, 2016.

40. Zhao LY, Xu WL, Xu ZQ, Qi C, Li Y, Cheng J, Liu LK, Wu YN, Gao J and Ye JH: The overexpressed functional transient receptor potential channel TRPM2 in oral squamous cell carcinoma. Sci Rep 6: 38471, 2016.

41. Duan T, Sun W, Zhang M, Ge J, He Y, Zhang J, Zheng Y, Yang W, Shen HM, Yang J, et al: Dietary restriction protects against diethylnitrosamine-induced hepatocellular tumorigenesis by restoring the disturbed gene expression profile. Sci Rep 7: 43745, 2017.

42. Livak KJ and Schmittgen TD: Analysis of relative gene expression data using real-time quantitative PCR and the 2(-Delta Delta C(T)) method. Methods 25: 402-408, 2001.

43. Simon F, Varela D and Cabello-Verrugio C: Oxidative stress-modulated TRPM ion channels in cell dysfunction and pathological conditions in humans. Cell Signal 25: 1614-1624, 2013.

44. Miller BA and Cheung JY: TRPM2 protects against tissue damage following oxidative stress and ischaemia-reperfusion. J Physiol 594: 4181-4191, 2016.

45. Yang C, Tan YX, Yang GZ, Zhang J, Pan YF, Liu C, Fu J, Chen Y, Ding ZW, Dong LW and Wang HY: Gankyrin has an antioxidative role through the feedback regulation of Nrf2 in hepatocellular carcinoma. J Exp Med 213: 859-875, 2016

46. Blokhina O, Virolainen E and Fagerstedt KV: Antioxidants, oxidative damage and oxygen deprivation stress: A review. Ann Bot 91: 179-194, 2003.

47. Vinothini G and Nagini S: Correlation of xenobiotic-metabolizing enzymes, oxidative stress and NFkappaB signaling with histological grade and menopausal status in patients with adenocarcinoma of the breast. Clin Chim Acta 411: 368-374, 2010

48. Chen CY, Liu TZ, Liu YW, Tseng WC, Liu RH, Lu FJ, Lin YS, Kuo SH and Chen CH: 6-shogaol (alkanone from ginger) induces apoptotic cell death of human hepatoma p53 mutant Mahlavu subline via an oxidative stress-mediated caspase-dependent mechanism. J Agric Food Chem 55: 948-954, 2007.

49. Zhang K, Jiao K, Xing Z, Zhang L, Yang J, Xie X and Yang L: $\mathrm{Bcl}-\mathrm{xL}$ overexpression and its association with the progress of tongue carcinoma. Int J Clin Exp Pathol 7: 7360-7377, 2014. 